\title{
Surface integrity of Mg-based nanocomposite produced by abrasive water jet machining (AWJM)
}

\author{
K. Bimla Mardi ${ }^{1 *}$, A. R. Dixit ${ }^{1}$, A. Mallick ${ }^{1}<$ Indian Authors $>^{-}$
}

Alokesh Pramanik ${ }^{2}<$ Curtin University $>$

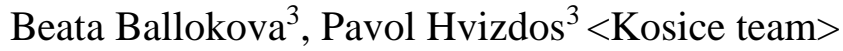

Josef Foldyna ${ }^{4}$, Jiri Scucka ${ }^{4}$, Petr Hlavacek ${ }^{4}$, Michal Zelenak $^{4}<$ Czech Republic $>$

${ }^{1}$ Department of Mechanical Engineering, Indian Institute of Technology (Indian School of Mines), Dhanbad, Jharkhand-826004, India

${ }^{2}$ Department of Mechanical Engineering, Curtin University, Bentley, WA, Australia

${ }^{3}$ Slovak Academy of Sciences, Institute of Materials Research, Watsonova 47, Kosice- 04001, Slovakia

${ }^{4}$ Department of Material Disintegration, Institute of Geonics of the CAS, v.v.i., Ostrava 70800 , Czech Republic

\section{Abstract}

This paper investigates the influence of jet traverse speed on the surface integrity of $0.66 \mathrm{wt} \%$ $\mathrm{Al}_{2} \mathrm{O}_{3}$ nanoparticle reinforced metal matrix composite (MMC) generated by Abrasive Water Jet Machining(AWJM). Surface morphology, surface topography and surface roughness (SR) of the AWJ surface was analyzed. The machined surfaces of the nanocomposites were examined by laser confocal microscope and field emission scanning electron microscope (FESEM). Microhardness and elasticity modulus measurement by nanoindentation testing were also performed across thickness of the samples to see depth of the zone, affected by AWJ cutting. The result reveals that extent of grooving by abrasive particle and irregularity in AWJ machined surface increases as the traverse speed increased. Similarly, the rise in value of surface roughness parameters with traverse speed was also seen. In addition, nanoindentation testing represents the lower hardness and elastic modulus due to softening occurs in AWJ surface.

Keywords: Mg-based, nanocomposite, Machinability, AWJM, Surface, topography, roughness, nanoindentation

\section{INTRODUCTION}

Currently, Magnesium based metal matrix composites (Mg-MMCs) are becoming prominent for numerous industrial applications owing to their good electrical and thermal conductivities, superior specific strength and stiffness, lower density, enhanced mechanical and tribology 
1 properties, superior machinability, excellent castability etc. compared to their monolithic 2 materials [1-4]. However, main drawback of $\mathrm{Mg}$ based MMC is deterioration in the ductility of 3 the material with high volume fraction of particles. Whereas, Magnesium based metal matrix 4 nanocomposites (Mg-MMNCs) retain good ductility along with improved yield and ultimate 5 strength [5, 6]. Therefore, researchers are giving their attention to these materials. Literature shows these materials can be processed successfully by several methods such as, stir-casting method [7] followed by equal channel angular extrusion, disintegrated melt deposition (DMD) method followed by hot extrusion [8-9], semi solid stirring assisted ultrasonic vibration [10], powder metallurgy [11], friction stir process (FSP) [12] etc. The usage of Mg based composites is increasing constantly as it can solve problems faced by automobile, aviation and telecommunication industries where the ratio between strength and weight is an important factor.

The poor machinability of these materials, limit its use in industries. In addition, the difficulties in traditional machining of MMCs lie in the desired tolerances and surface properties because hard ceramic reinforcements cause serious abrasion of the tool that result into unacceptable short tool life and this directly affect the manufacturing cost [13-14]. On the other side, the nontraditional machining technique like abrasive water jet machining provides better properties of machining compared to other traditional machining methods [15]. AWJ technology can machine almost all types of material and is best suited for hard to cut materials and thermally sensitive materials [16]. The material removal process in AWJM occurs by means of erosion. The erosion is caused by grit abrasives entrained in high velocity water jet. The material removal process comprised with microchip formation, abrasive scooping, ploughing and rubbing, all of which occurs by means of shear deformation [17]. This machining process provides various distinct advantages like high machining versatility, small cutting forces, omni-directional cutting capability, high cutting speeds and no thermal deformation [15, 18-19].

The abrasive water jet machining is an advanced technique, that was successful used for processing wide range of materials such as AA5083-H32 aluminium alloy [20], brass-360 [21], nickel based superalloy [22], Stainless Steel AISI 304 [23] etc. However, Very few literatures are available on AWJM of MMCs materials. Muller and Monaghan [15] reported the machining characteristics of $\mathrm{Al} / \mathrm{SiC}$ particulate reinforced composites using $\mathrm{AWJM}$, Laser and Electric Discharge Machining (EDM). They reported that the AWJM process does not induce high 
temperatures as compared to other thermal machining processes (laser, EDM). Hence, there is no thermal damage on the machined surface and there is only minimum sub-surface damage on the composite. However, the surface generated through AWJM, generally possesses poor surface finish and smoother surface is attributable to lower feed rates. This is the main limitations of this machining process. Srinivas et al. [24] have conducted a study to estimate the penetrability of abrasive water jets on aluminium alloy/SiC composite material and concluded that, harder materials offer higher resistance to the jet due to their increased mechanical properties. At an increased flow rate of abrasive and higher water jet pressure, the depth of penetration also increases. This happens because the jet possesses the maximum energy during higher water pressure and with greater numbers of particles gets a chance to erode the target material with high flow rate of abrasives. Kumar and Kumaresan [25] investigated the machinability of Albased $\mathrm{SiC}$ composite using AWJM, fabricated by stir casting method. They analyzed the effect of $\mathrm{SiC}$ reinforcement particle on machining process. They also examined and compared the influence of pressure of water jet, nozzle traverse speed and standoff distance on SR of the composite material with different compositions. They used Taguchi's design of experiments to observe the recommended parametric condition for optimum SR. The main findings are the Traverse Speed is one of the significant factors on SR whereas water jet pressure and stand-off distance are least significant. Pramanik [26] presented an extensive review on non-traditional machining of MMCs materials. He analyzed the machining mechanism, cutting speed and surface finish during AWJM of MMCs. From this study he concluded that the mechanism of AWJM is dependent on the proportional size of the reinforcement and abrasive particles. The cutting wear is dominant feature during AWJM. The fracture and pull out of reinforcement particle may occur, when the abrasive particles are bigger than the reinforced particle and the surface finish is affected highly by abrasive rather than reinforced particle. In the case of comparable sizes between abrasive and reinforcement particles, indentation, ploughing and pushing of particles into the matrix generally occurs. Kok et al. [27] have proposed the Genetic

27 Expressions Programming for predicting the SR as a function of characteristics of work piece material viz. particle size, weight fraction of particle and depth of cut in AWJM of 7075 $\mathrm{Al} / \mathrm{Al}_{2} \mathrm{O}_{3}$ composites. Hashish [19] presented the discussion on AWJ machining (turning, drilling, milling, linear cutting) of advance composites. Hamatani and Ramulu [28] presented a 
matrix composites through AWJM. They examined the surface roughness (Ra) with respect to

2 speeds. The influence of abrasive mesh size and flow rate of abrasive on Ra values was also noted in MMC. It was seen that the Ra increases with traverse rate and decreases with bigger size of abrasive. The good surface finish was observed with lower traverse rate and lower mass flow rate of abrasive setting whereas surface finish become worsen at higher setting of traverse rate and higher flow rate of abrasive. The surface softening was also occurred during machining at higher traverse speed and smaller size of abrasive. The explanation was not given. Savrun and

8 Taya [29] focused on machinability of $\mathrm{SiC}$ whisker/2124 aluminium matrix composite with an AWJ. They discussed the surface finish with respect to traverse speed. They observed that SR increases with traverse speed. Embedment of abrasive particle into matrix and micromelting of matrix material at higher traverse speed was also noticed. Work-hardening was not observed in machined composite. Best of the author knowledge the literatures are not reported so far on the machining characteristics of Mg-based nanocomposite during AWJM.

The objective of this proposed work is to investigate the effectiveness of non-conventional machining process viz. AWJM during machining 0.66 weight fraction $\mathrm{Mg}-\mathrm{MMNC}$. The machining outcomes on these nanocomposites are discussed in terms of surface topography as a function of traverse speed. Surface integrity after machining is also examined by nanoindentation testing. According to the results observed during the experiments, some concluding remarks regarding feasibility of machining method are also given.

\section{MATERIALS AND METHODS}

21 In this study, 6\% Al (purity 99.9\%) balanced by Mg (purity 99.9\%) provided by Alfa Aesar 22 (Massachusetts, USA) was used as matrix material. The $\mathrm{Al}_{2} \mathrm{O}_{3}$ nanoparticles (average particle size $\sim 50 \mathrm{~nm}$ ) were used as reinforcement supplied by Baikowski (Japan). The weight fraction of

24 reinforcement particles added into the matrix material was 0.66 . The material was fabricated by DMD method followed by hot extrusion [5].

\section{Abrasive water jet machining}

27 The AWJM process was performed on PTV: CNC WJ2020B-1Z-D machine. The cutting was performed in three different levels (i.e., low, medium and high) of cutting speeds, $v_{t}=20,250$, $500 \mathrm{~mm} / \mathrm{min}$. The machining parameters were selected based on the pilot experiment. The 
cutting conditions during experiments are displayed in Table 1. A detail sketch of cutting head of AWJ machine is shown in Fig. 1 and Fig. 2 illustrates the experimental photo of cutting process. After machining, the morphology of the machined surfaces was investigated using Olympus LEXT OLS 3100 laser confocal microscope. The surfaces were further studied by Field emission scanning electron microscope (FESEM) to observe the machined surface at a higher resolution.

\section{Optical profilometer MicroProf FRT}

The machined samples to be examined were obtained after performing AWJM as per the setting parameters. In present study, three different processed surfaces machined at traverse speeds of 20, 250 and $500 \mathrm{~mm} / \mathrm{min}$ were studied. Selected amplitude parameters were analyzed by optical profilometer. In this study, average roughness $(\mathrm{Ra})$, maximum height of peak (Rp), root mean square roughness $(\mathrm{Rq})$, maximum depth of valleys $(\mathrm{Rv})$, ten-point height $(\mathrm{Rz})$ of all machined surfaces were examined. All parameters were measured by MicroProf FRT according to EN ISO 4287, then findings were analysed by SPIP software.

\section{Nanoindentation testing}

The nanoindentation test was performed on samples of $\mathrm{Mg}-6 \mathrm{Al} / 0.66 \% \mathrm{Al}_{2} \mathrm{O}_{3}$ material after machining to determine the elastic modulus and hardness of the materials. Testing was done on the Agilent G200 Nanoindenter and Berkovich indenter tip was used. For testing, the samples were cut in half, as sketched in Fig. 3. The cross-section was polished to mirror finish and test was performed. Three rows of 10 indents were made at the same distance, with step of $5 \mu \mathrm{m}$ (Fig. 3). For testing single loading-unloading mode was used. The maximum load for each indent was $100 \mathrm{mN}$ (with final depth of penetration typically about $2000 \mathrm{~nm}$ ), then values of Hardness and elasticity modulus were measured and averaged.

\section{Mechanical properties}

The fabricated nanocomposites were characterized to know the mechanical properties. The density measurements were done on randomly selected polished samples by Archimedes' principle. The distilled water used as immersion fluid. The nano-indentation testing was conducted on mirror-polished samples using XP-Nanoindenter (Agilent, USA) in continuous 
stiffness mode (CSM) for measuring hardness and modulus. A Berkovich indenter having effective cone angle $70.3^{\circ}$ is used for testing. The strain rate was fixed at $0.05 \mathrm{~s}^{-1}$ during experiments and final depth of penetration fixed at typically about $2000 \mathrm{~nm}$. Up to 5 indentations were made and the obtained data were statistically evaluated. The mechanical and physical properties of material are listed in Table 2. Nanoindentation experiment was also performed in unreinforced $\mathrm{Mg}$ material for comparing the hardness and modulus values.

\section{RESULTS AND DISCUSSION}

The outcomes of this research work includes the observation and analysis of surface morphology, surface roughness and nano-indentation testing (Measurement of hardness and elasticity) of the machined surfaces.

\section{Surface morphology}

The typical as machined surface (2D surface detail) is shown in Fig. 4 obtained by Olympus LEXT OLS 3100 laser confocal microscope. Machined surfaces are composed of pronounced micro-cutting traces created by abrasive particles. The traces are oriented towards the direction of water jet flow. The lengths of traces are approximately same and are almost parallel. Some of the traces are slightly curved. Long narrow and short wide traces are also dispersed among the major traces. At slow speed, sometimes the traces are interrupted by short narrow grooves oriented perpendicular or obliquely to the traces. Additionally, the traces often overlap each other due to interaction between abrasive particles which is responsible for good surface finish at slow traverse speed. At higher speed the cutting traces become more pronounced and widens. There are also small oval depressions sparsely dispersed on the machined surface at higher speed. There are no visible plastic deformations on the surface. The corresponding 3D surface texture of the machined surfaces at different traverse speeds were analysed by Olympus LEXT OLS 3100 laser confocal microscope, shown in Fig. 5.

For better resolution, machined surfaces were examined by FESEM (Fig. 6). The cutting wear is the major cause in material removal process and ductile shearing of matrix material by abrasive scooping and ploughing path is also observed. From FESEM photograph, it is clear that extent of grooving and severity of the surface features also increases with traverse speed in the machined surfaces. This result is similar with earlier studies [29]. From the Fig. 6, it is evident that the 
surface morphology is almost regular at traverse speed of $20 \mathrm{~mm} / \mathrm{min}$ and $250 \mathrm{~mm} / \mathrm{min}$. But at higher traverse speed $(500 \mathrm{~mm} / \mathrm{min})$ the surface got more damaged by abrasive particles resulted into irregular or bigger grooves. It is natural that at lower traverse speed, the machined surface gets more time to be abraded, therefore the more material is removed progressively and the machined surface becomes smoother having less striation. The size of the abrasives is reasonably large $(0.177 \mathrm{~mm}$ for mesh size 80$)$ compare to the reinforced particles. Therefore, several reinforcement particles removed by a single abrasive particle. The fracture and pull out of reinforced particles may happen [15] when those are partially in the path of abrasive particles and partially in the matrix material. In that situation the effect of reinforcement particles is negligible as compare to the effect of abrasive particle on the surface finish of the material [19]. Surfaces were further analyzed in terms of amplitude roughness parameters in next section.

The machined surface is full of grooves, this may be due to sliding of particles and embedded abrasive particles into the matrix. The higher magnification FESEM photograph of grooves captures the embedded abrasive particles into the metal matrix shown in Fig. 7. The embedded particle in machined surface is garnet particle that was corroborated by Energy Dispersive Spectroscopy (EDS) analysis. In Fig. 7 the Fe/Mn peaks can be clearly seen, that denoting the garnet composition.

The impingement of abrasive particles on the workpiece surface generates localized high temperature which may melt the matrix materials. In case of lower traverse speed, the cooling effect of the fluid minimizes the micro-melting but at higher traverse speed the micro-melting is noticeable. Fig. 8 represents the micro-melting on the AWJ surface machined at $500 \mathrm{~mm} / \mathrm{min}$ speed. In this case, the surface appearance changes completely.

\section{Surface Roughness}

The roughness measurement of machined surface is performed on optical profilometer. The amplitude parameters ( $\mathrm{Ra}, \mathrm{Rp}, \mathrm{Rq}, \mathrm{Rv}, \mathrm{Rz})$ are used to measure vertical characteristics of the surface deviations. The 3D plot of surface topography is acquired from 10 numbers of lines spaced by $0.5 \mathrm{~mm}$. Fig. 9 (a-e) demonstrates the influence of traverse speeds on SR values at constant mass flow rate of abrasive. It is noticed that with the increase of traverse speed, surface roughness increases. This happens due to at higher traverse speed lesser number of abrasive 
particles impinges on cutting surface due to smaller interaction time between abrasive jet and work-piece. Whereas, at lower speeds more number of abrasive particles impinges on cutting surface due to more interaction time between abrasive jet and work-piece and therefore, better surface finish is observed. This result can be correlated with the earlier surface topography (Fig. $6)$.

Variation in average surface roughness $(\mathrm{Ra})$ in all three surfaces is shown in Fig. 9(a). The surface roughness $(\mathrm{Ra})$ values obtained at traverse speed $20 \mathrm{~mm} / \mathrm{min}, 250 \mathrm{~mm} / \mathrm{min}$ and 500 $\mathrm{mm} / \mathrm{min}$ are $3.5 \mu \mathrm{m}, 5.5 \mu \mathrm{m}$ and $12 \mu \mathrm{m}$, respectively. An alteration of about $0.4 \mu \mathrm{m}$ is noted in the minimum and maximum value of $\mathrm{Ra}$ in all surfaces. There is no notable changes was observed in $\mathrm{Ra}$ value within the assessment length. It represents regular surfaces produced by AWJM. The difference between Ra value at 20 and $500 \mathrm{~mm} / \mathrm{min}$ speed is around $8-9 \mu \mathrm{m}$. Hence, at $20 \mathrm{~mm} / \mathrm{min}$ speed best surface roughness can be achieved. The main cause for minimum Ra at $20 \mathrm{~mm} / \mathrm{min}$ as compared to $\mathrm{Ra}$ at $500 \mathrm{~mm} / \mathrm{min}$ is the fact that cutting grooves produced by each and every abrasive particle are regular and smaller in size in former case.

Fig. 9(b) shows the root mean square roughness (Rq) with respect to all three traverse speeds. A similar trend was observed in $\mathrm{Rq}$ and $\mathrm{Ra}$. The minimum $\mathrm{Rq}$ value is attained with $20 \mathrm{~mm} / \mathrm{min}$ speed, maximum value with $500 \mathrm{~mm} / \mathrm{min}$ and mid value with $250 \mathrm{~mm} / \mathrm{min}$ speed. There is a large difference in $\mathrm{Rq}$ values at maximum and minimum speed i.e 12-13 $\mu \mathrm{m}$. Fluctuations in $\mathrm{Rq}$ values at 20, 250 and $500 \mathrm{~mm} / \mathrm{min}$ speeds are $0.2,0.4$ and $1.6 \mu \mathrm{m}$ respectively. Hence, no appreciable changes were noticed in profile for Rq. A similar trend was also noticed in the tenpoint height $(\mathrm{Rz})$ parameter as shown in Fig. 9 (c). Variation in maximum and minimum $\mathrm{Rz}$ value for all three surfaces are around 3.8-4 $\mu \mathrm{m}$. Therefore, no appreciable fluctuation in profile was noticed. Fig. 9(d) and 9(e) shows maximum height of peak (Rp) and maximum depth of valley (Rv) parameters respectively. Figures are showing almost similar trend. In case of Rv values are very close for the surfaces machined at 20 and $250 \mathrm{~mm} / \mathrm{min}$ speed. However, corresponding values of $\mathrm{Rv}$ are higher as compare to Rp values in abrasive water jet cut surface for all three different traverse speeds. Fig. 10 shows the 2D and 3D visualization of AWJ surface machined at $500 \mathrm{~mm} / \mathrm{min}$ captured by MicroProf FRT.

Additionally, this was also observed that the surface roughness of the nanocomposites is mainly affected by micro effects of each impacting particles. Since, reinforcing particles $(50 \mathrm{~nm})$ in this 
1 composite are much smaller than the abrasive particle $(0.177 \mathrm{~mm})$ that impacting the matrix

2 material. So, the nanoparticles will have little or no effects on machined surface finish.

\section{$3 \quad$ Nanoindentation testing}

4 To see the effect of AWJ machining in the nanocomposite, nano-indentation test was performed 5 for micro-hardness and elasticity modulus measurements. The measurements were conducted upto $50 \mu \mathrm{m}$ depth from the machined surface across the thickness. The results of the hardness and

7 modulus test are shown in Fig. 11. From graph it seems to be around 20-25 $\mu \mathrm{m}$ deep affected 8 zones under surfaces. This may be attributed to softening of material during AWJ machining.

9 The softening of the material during AWJ machining was also observed by other researchers 10 [19]. The hardness and modulus values in up to $25 \mu \mathrm{m}$ depth ranges from 0.8-1.0 GPa and 42-45 $11 \mathrm{GPa}$ respectively. These values are resembles to the hardness and modulus values of 12 unreinforced material (Table. 1). Up to the depth of $25 \mu \mathrm{m}$ both the values are inconsistent, after $1325 \mu \mathrm{m}$ depth values are consistent. The possible reason for this is may be resulted from the pull out of reinforcement particles during machining, since the reinforcement particle size is much smaller than abrasive particles [26]. Hence, it is showing almost similar values as pure one after machining.

17 The surface machined by AWJ got lower hardness and elastic modulus though the variation of 18 these parameters is significant in the same machined layers. The progressive abrasion of the machined surface releases the residual stress in the surface which relaxes the materials and,

20 hardness and elastic modulus reduce. In addition localized grooving and striation allow the 21 material to deform easily during hardness test which give lower hardness and elastic modulus.

22 The higher readings of hardness on the machined surface arise due the testing of hardness on the 23 embedded hard abrasive or reinforced particles.

26 In this study, the machinability aspects of $\mathrm{Mg}-6 \mathrm{Al}$ alloy matrix reinforced with 0.66 wt. $\% \mathrm{Al}_{2} \mathrm{O}_{3}$ 27 nanoparticles was carried out during AWJM. The experimental results were analyzed and 
compared under varying traverse speeds. Based on the investigation on feasibility of machining of nanocomposite, following conclusions can be drawn:

1. AWJ machining seems to be promising machining method for $0.66 \mathrm{wt} \% \mathrm{Al}_{2} \mathrm{O}_{3}$ nanoparticle reinforced $\mathrm{Mg}$ based MMC with good surface finish and minimum subsurface damage. However, micro-melting at high traverse speed and abrasive particle embedment into the metal matrix was observed.

2. The AWJ cut surface ensures the uniform surface topography at $20 \mathrm{~mm} / \mathrm{min}$ and 250 $\mathrm{mm} / \mathrm{min}$ speeds. Whereas, at $500 \mathrm{~mm} / \mathrm{min}$ speed the surface finish deteriorates due to insufficient cutting by abrasive particles at higher speed.

3. According to amplitude parameters ( $\mathrm{Ra}, \mathrm{Rq}, \mathrm{Rz}, \mathrm{Rp}, \mathrm{Rv})$ selected for analysis, it confirms that surface parameters values decrease as traverse speed decreases from $500 \mathrm{~mm} / \mathrm{min}$ to $20 \mathrm{~mm} / \mathrm{min}$. At some extant, it ascertain the better surface quality could be achieved at lower speed.

4. In the AWJ machined surface, the decrease in hardness and elasticity modulus values was noticed up-to the depth of 20-25 $\mu \mathrm{m}$ from machined surface. It represents the softening of the material occurred during machining.

\section{ACKNOWLEDGEMENTS}

The authors are thankful to Dr. M. Gupta, Dept. Mechanical Engineering, National University of Singapore for providing material.

\section{REFERENCES}

1. Cao, G.; Konishi, H.; Li, X. Mechanical properties and microstructure of SiC-reinforced Mg-(2,4)Al-1Si nanocomposites fabricated by ultrasonic cavitation based solidification processing. Materials Science and Engineering A 2008, 486(1-2), 357-362.

2. Balakrishnan, M.; Dinaharan, I.; Palanivel, R.; Sivaprakasam, R. Synthesize of AZ31/TiC magnesium matrix composites using friction stir processing. Journal of Magnesium and Alloys 2015, 3(1), 76-78. 
3. Yao, Y.; Chen, L. Processing of B4C Particulate-reinforced Magnesium-matrix Composites by Metal-assisted Melt Infiltration Technique. Journal of Materials Science and Technology 2014, 30(7), 661-665.

4. Ye, H.Z.; Liu, X.Y. Review of recent studies in magnesium matrix composites. Journal of Materials Science 2004, 39 (20), 6153 - 6171.

5. Gupta, M.; Wong, W.L.E. Magnesium-based nanocomposites: Lightweight materials of the future. Materials Characterization 2015, 105, 30-46.

6. Gopalakannan, S.; Senthilvelan, T. Application of response surface method on machining of Al-SiC nano-composites. Measurement 2013, 46 (8), 2705-2715.

7. Huang, S.J.; Lin, P.C.; and Aoh, J.N. Mechanical Behavior Enhancement of AM60/A12O3p Magnesium Metal-Matrix Nanocomposites by ECAE. Materials and Manufacturing Processes 2015, 30 (10), 1272-1277.

8. Nguyen, Q.B.; Sim, Y.H.M.; Gupta, M.; Lim, C.Y.H. Tribology characteristics of magnesium alloy AZ31B and its composites. Tribology International 2015, 82, 464-471.

9. Suresh, K.; Dharmendra, C.; Rao , K. P.; Prasad, Y. V. R. K.; Gupta, M. Processing Map of AZ31-1Ca-1.5 vol.\% Nano-Alumina Composite for Hot Working. Materials and Manufacturing Processes 2015, 30, 1161-1167.

10. Nie, K.B.; Wang X.J.;Wu. K.; Xu, L.; Zheng, M.Y.; Hu, X.S. Processing, microstructure and mechanical properties of magnesium matrix nanocomposites fabricated by semisolid stirring assisted ultrasonic vibration. Journal of Alloys and Compound 2011, 509 (35), 8664-8669.

11. Selvam, B.; Marimuthu, P.; Narayanasamy, R.; Anandakrishnan, V.; Tun, K.S.; Gupta, M.; Kamaraj, M. Dry sliding wear behaviour of zinc oxide reinforced magnesium matrix nano-composites. Materials and Design 2014, 58, 475-481.

12. Ma, C.; Chen, L.; Xu, J.; Fehrenbacher, A.; Li, Y.; Pfefferkorn, F.E.; Duffie, N.A.; Zheng, J.; Li, X. Effect of fabrication and processing technology on the biodegradability of magnesium nanocomposites. Journal of Biomedical Materials Research 2013, 101B (5), 870-877.

13. Zhang, C. Effect of wire electrical discharge machining (WEDM) parameters on surface integrity of nanocomposite ceramics. Ceramics International 2014, 40, 9657-9662. 
14. Pramanik, A.; Zhang, L.C.; Arsecularatne, J.A. Prediction of cutting forces in machining of metal matrix composites. International Journal of Machine Tools and Manufacturing 2006, 46 (14), 1795-1803.

15. Muller, F.; Monaghan, J. Non-conventional machining of particle reinforced metal matrix composite. International Journal of Machine Tools and Manufacturing 2000, 40 (9), 1351-1366.

16. Kovacevic, R.; Hashish, M.; Mohan, R.; Ramulu, M.; Kim, T.J.; Geskin, E.S. State of the art of research and development in abrasive waterjet machining. Journal of Manufacturing Science and Engineering 1997, 119 (4B), 776-785.

17. Arola, D.; Ramulu, M. Material removal in abrasive waterjet machining of metals Surface integrity and texture. Wear 1997, 210 (1-2), 50-58.

18. Hascalik, A.; Caydas, U.; Gurun, H. Effect of traverse speed on abrasive waterjet machining of Ti-6Al-4V alloy. Materials and Design 2007,28 (6), 1953-1957.

19. Hashish, M. Waterjet machining of advanced composites. Materials and Manufacturing Processes 1995, 10 (6), 1129-1152.

20. Yuvaraja N.; Kumar, M. P. Multiresponse Optimization of Abrasive Water Jet Cutting Process Parameters Using TOPSIS Approach. Materials and Manufacturing Processes 2015, 30 (7), 882-889.

21. Babu, M. N.; Muthukrishnan, N. Investigation on Surface Roughness in Abrasive Water Jet Machining by the Response Surface Method. Materials and Manufacturing Processes 2014, 29 (11-12), 1422-1428.

22. Uthayakumar, M.; Khan, M. A.; Kumaran, S. T.; slota, A., Zajac, J. Machinability of nickel based superalloy by abrasive water jet machining. Materials and Manufacturing Processes 2016, 31(13), 1733-1739.

23. Singh, D.; Chaturvedi, V. Investigation of Optimal Processing Condition for Abrasive Water Jet Machining for Stainless Steel AISI 304 Using Grey Relational Analysis Coupled With S/N Ratio. Applied Mechanics and Materials 2014, 592-594, 438-443.

24. Srinivas S.; Babu, N.R. Penetration ability of abrasive waterjets in cutting of Aluminumsilicon carbide particulate metal matrix composites. Machining Science and Technology: An International Journal 2012, 16(3), 337-354. 
25. Kumar, B.A.; Kumaresan, G. Abrasive water jet Machining of aluminum-silicon carbide particulate Metal Matrix Composites. Advanced Materials and Manufacturing Processes for Strategic Sectors 2015, 830-831, 83-86. DOI: 10.4024/www.scientific.net/MSF.830831.83

26. Pramanik, A. Developments in the non-traditional machining of particle reinforced metal matrix composites. International Journal of Machine Tools \& Manufacture 2014, 86, 4461.

27. Kok, M.; Kanca, E.; Eyercioglu, O. Prediction of surface roughness in abrasive waterjet machining of particle reinforced MMCs using genetic expression programming. International Journal of Advance Manufacturing Technology 2011, 55(9), 955-968.

28. Hamatani, G.; Ramulu, M. Machinability of High Temperature Composites by Abrasive Waterjet. Journal of Engineering Materials and Technology 1990, 112(4), 381-386.

29. Savrun, E.; Taya, M. Surface characterization of SiC whisker/2124 aluminium and Al2O3 composites machined by abrasive water jet. Journal of Materials Science 1988, 23 (4), 1453-1458.

Figure No Figure Captions

Fig. 1 Schematic sketch of cutting head with used parameters

Fig. 2 Experimental setup of AWJ Cutting process

Fig. 3 Sample preparation for nanoindentation testing on AWJ machined surface, (a) A sample, with illustration of prepared cross sections, (b) Samples cut in half, embedded in metallographic resin, (c) Placing of indents

Fig. 4 The AWJ machined surfaces of $\mathrm{Mg}-6 \mathrm{Al} / 0.66 \quad \mathrm{Al}_{2} \mathrm{O}_{3}$ nanocomposites at three different speeds.

Fig. 5 3D surface detail of AWJ cutting surface at different traverse speeds.

Fig. 6 FESEM photograph of AWJ machined surface at different traverse speeds, $v_{t}=(a)$ 20 , (b) 250 , (c) $500 \mathrm{~mm} / \mathrm{min}$. The cutting direction is shown by white arrows.

Fig. 7 Higher magnification of Fig. 6(b) indicating abrasive particle embedded into the nanocomposite, confirmed by EDS. 
Fig. 8 Micro-melting of matrix material after AWJM at a traverse speed of $500 \mathrm{~mm} / \mathrm{min}$.

Fig. 9 Effect of traverse speeds on the selected amplitude (a-e) surface roughness parameters at constant abrasive mass flow rate $(300 \mathrm{~g} / \mathrm{min})$.

Fig. 10 Surface topographic image (a) 2D view, (b) 3D view of AWJ surface cut at 500 $\mathrm{mm} / \mathrm{min}$ speed.

Fig. 11 Hardness and modulus values as a function of distance of indentation (across thickness) from machined surface.

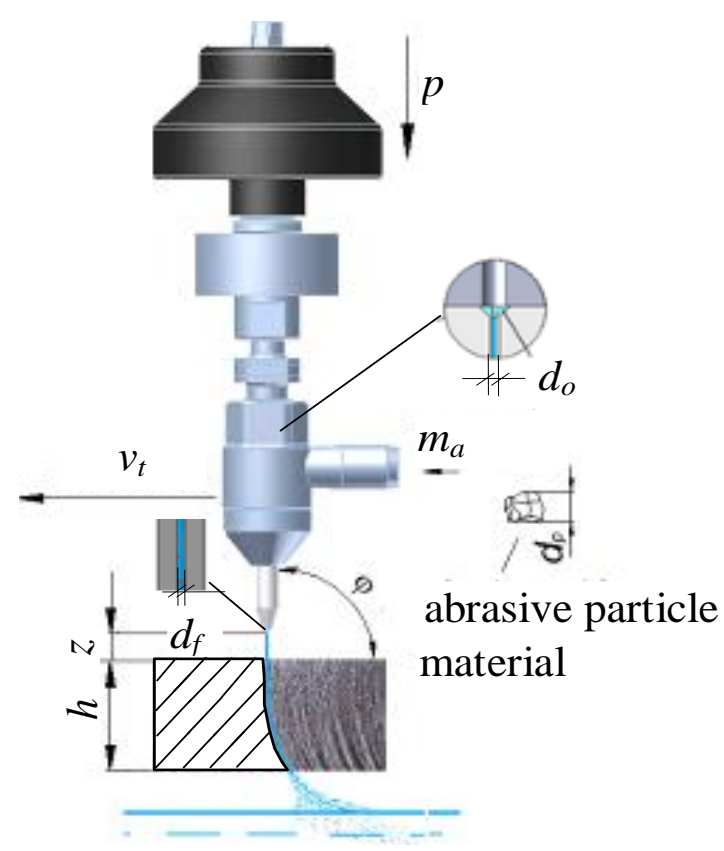

Fig.1 Schematic sketch of cutting head with used parameters 
1

2

3

4

5

6

7

8

9

10

11

12

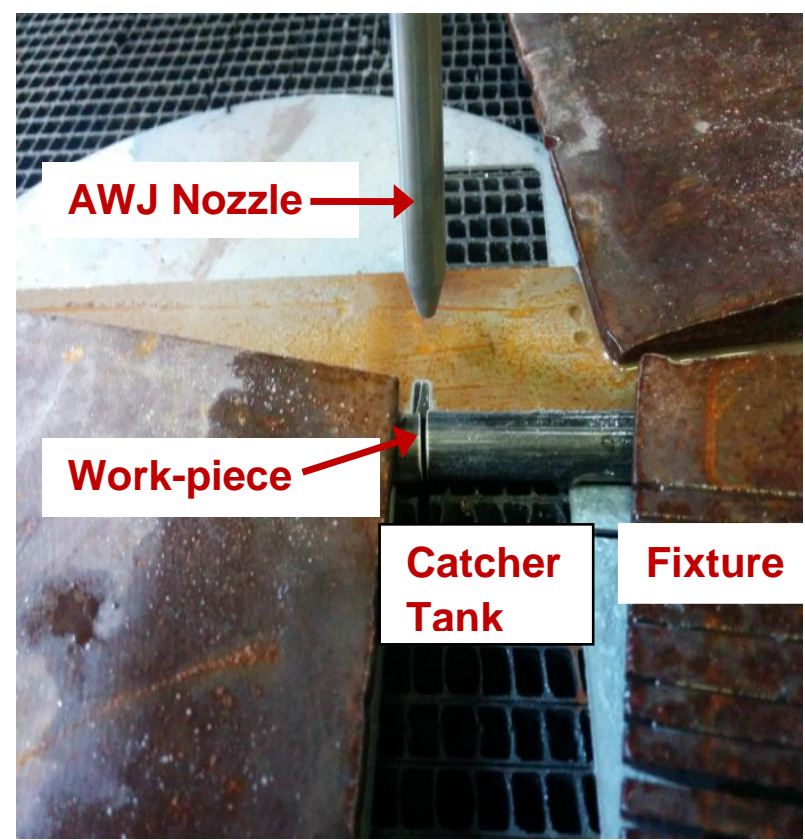



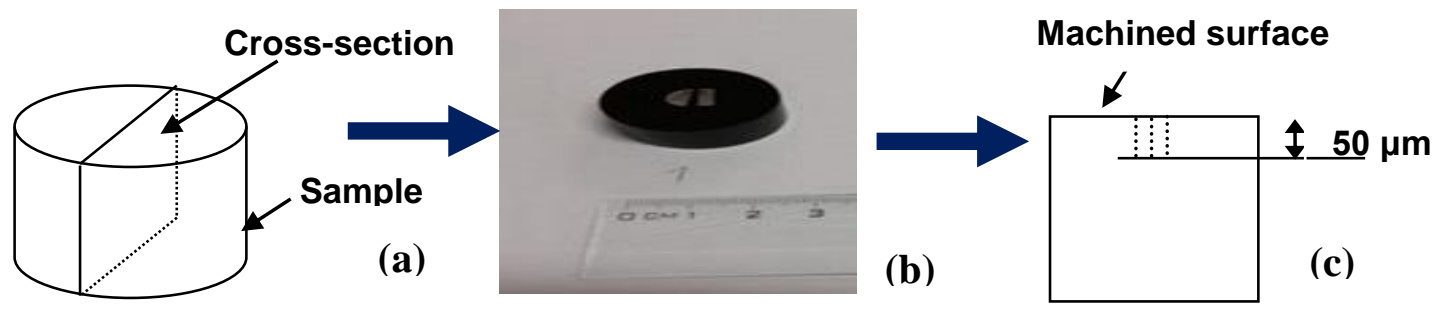

14

15

16 Fig.3. Sample preparation for nanoindentation testing on AWJ machined surface, (a) A sample, 17 with illustration of prepared cross sections, (b) Samples cut in half, embedded in metallographic resin, (c) Placing of indents 


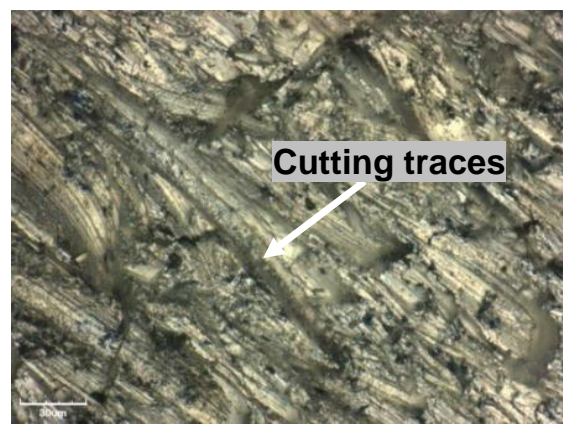

$20 \mathrm{~mm} / \mathrm{min}$

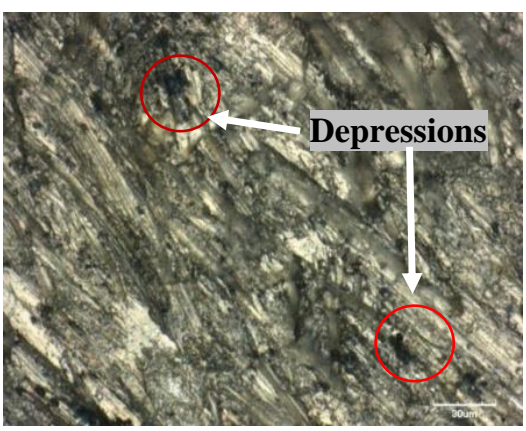

$250 \mathrm{~mm} / \mathrm{min}$

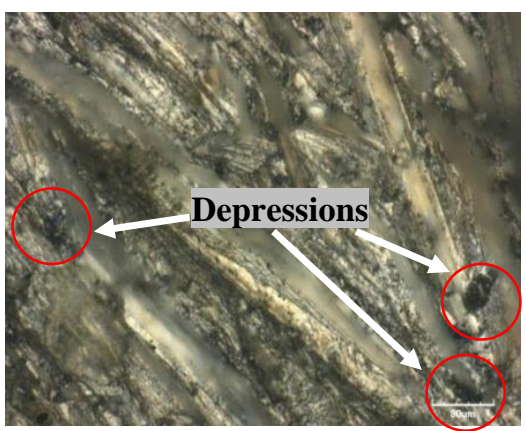

$500 \mathrm{~mm} / \mathrm{min}$

13 Fig. 4. The $\mathrm{AWJ}$ machined surfaces of $\mathrm{Mg}-6 \mathrm{Al} / 0.66 \mathrm{Al}_{2} \mathrm{O}_{3}$ nanocomposites at three different 14 speeds. 


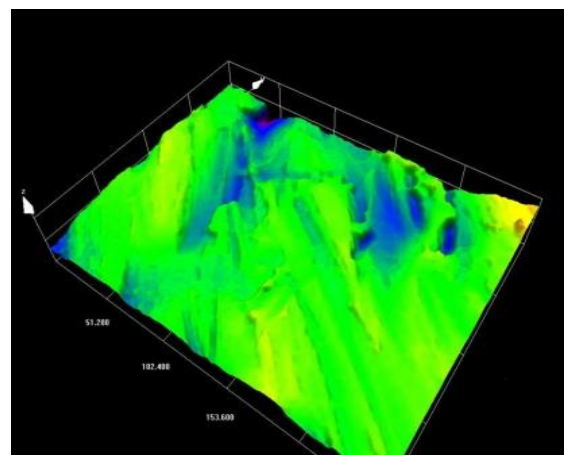

$20 \mathrm{~mm} / \mathrm{min}$

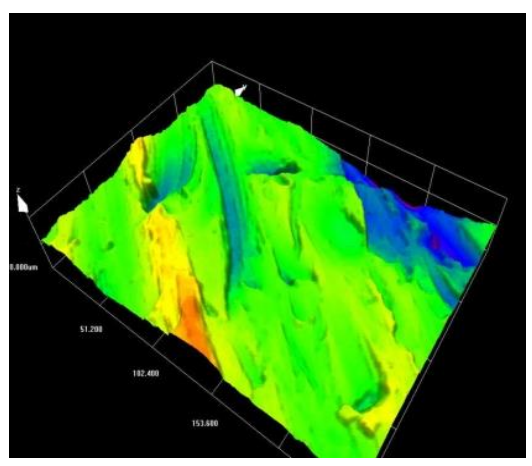

$250 \mathrm{~mm} / \mathrm{min}$

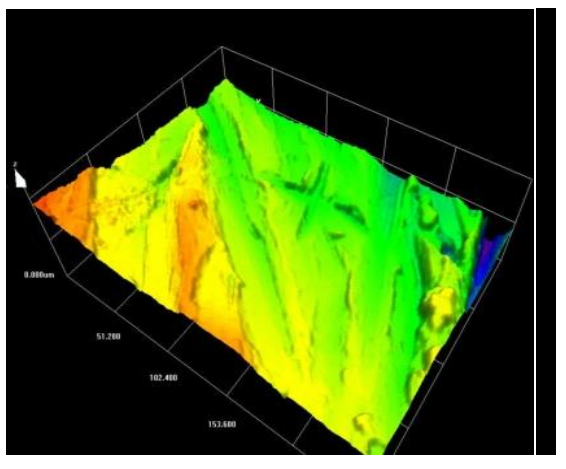

$500 \mathrm{~mm} / \mathrm{min}$

Fig. 5. 3D surface detail of AWJ cutting surface at different traverse speeds. 
1

2

3

4

5

6

7

8

9

10

11

12
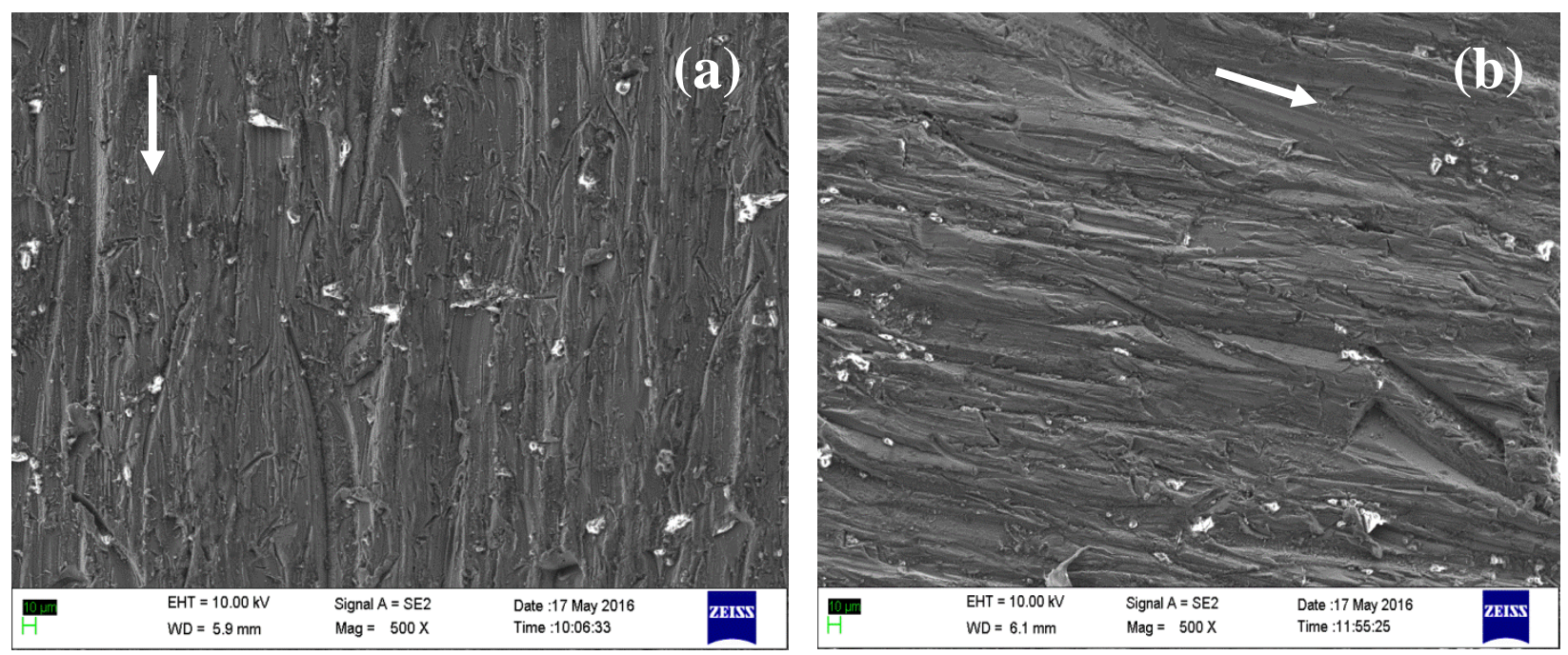


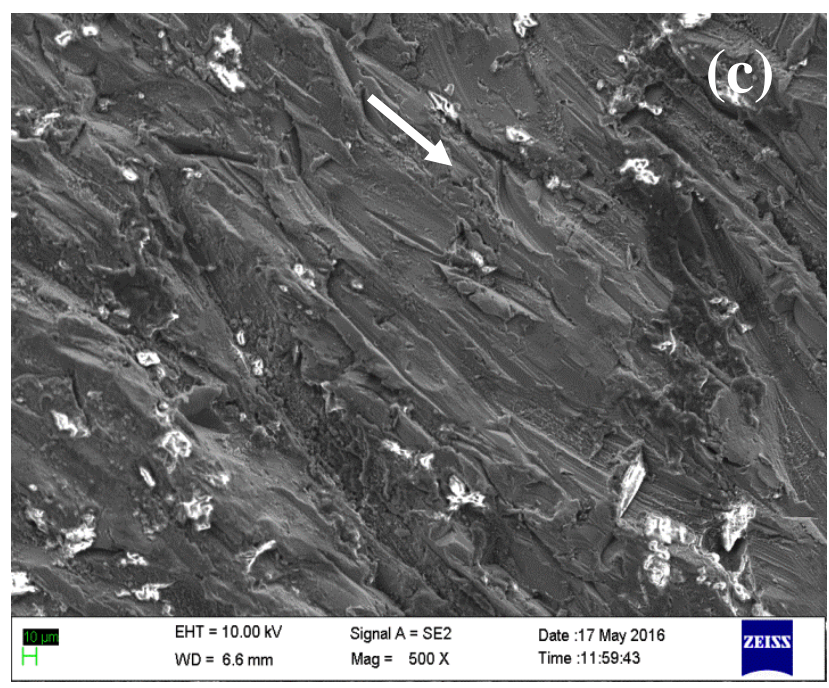

1

2

3 Fig. 6. FESEM photograph of AWJ machined surface at different traverse speeds, $v_{t}=(a) 20$, (b)

4250 , (c) $500 \mathrm{~mm} / \mathrm{min}$. The cutting direction is shown by white arrows.

5

6

7

8

9

10 

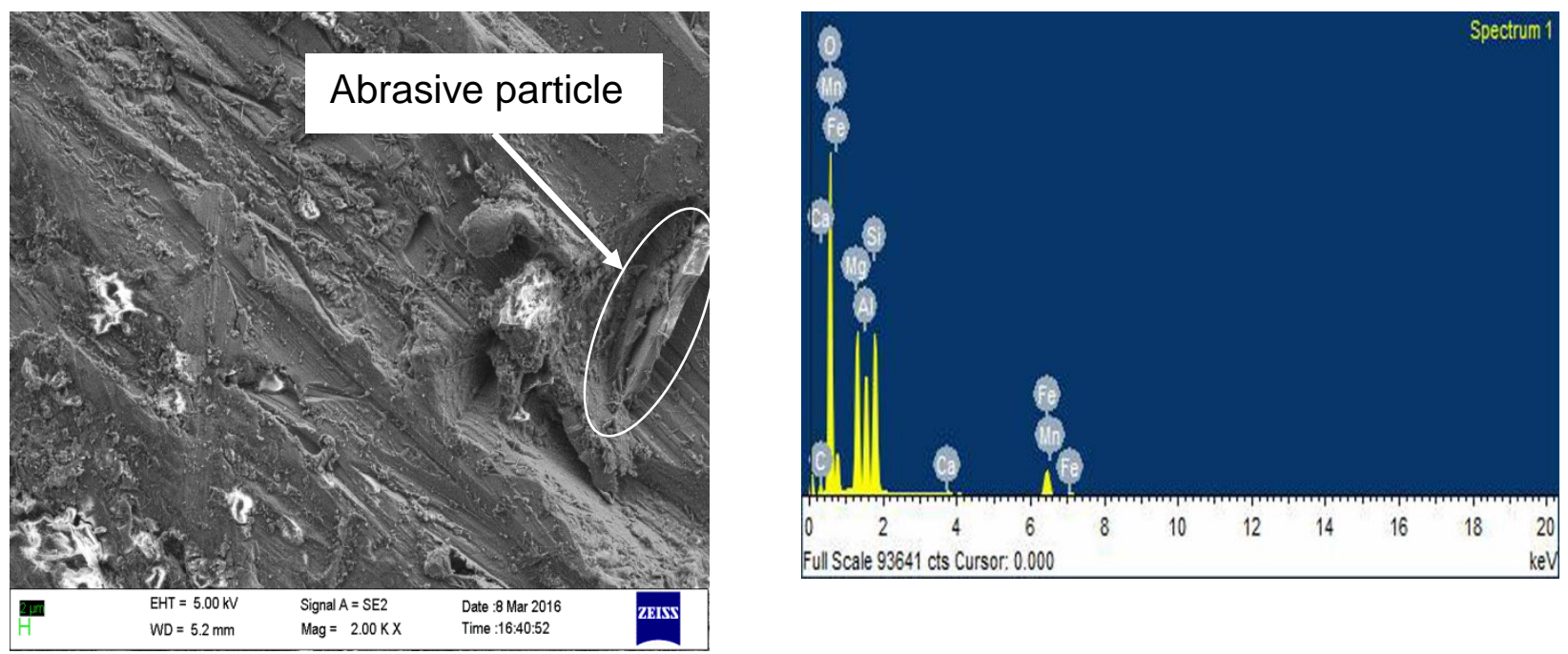

1

2 Fig. 7. Higher magnification of Fig. 6(b) indicating abrasive particle embedded into the 3 nanocomposite, confirmed by EDS.

4

5

6

7

8

9

10

11

12

13

14

15 


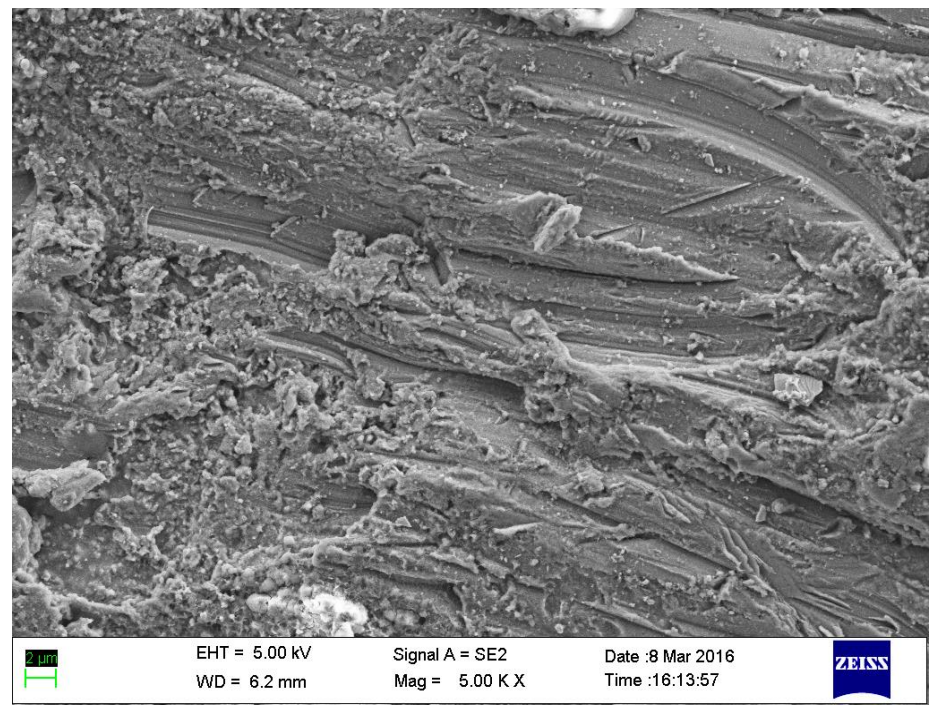

8

9 Fig. 8. Micro-melting of matrix material after AWJM at a traverse speed of $500 \mathrm{~mm} / \mathrm{min}$.

10

11

12

13

14

15

16 

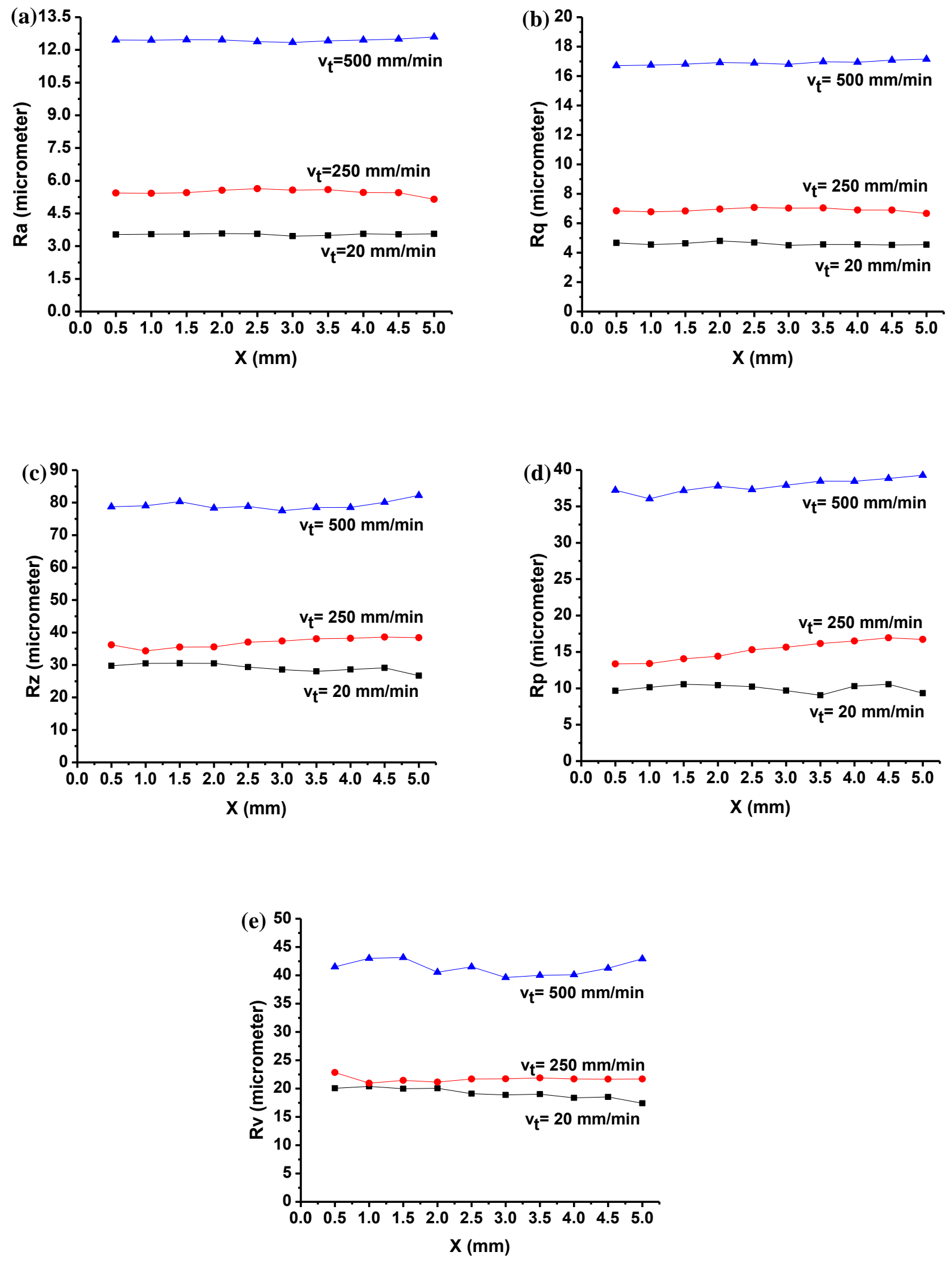
1 Fig. 9. Effect of traverse speeds on the selected amplitude (a-e) surface roughness parameters at 2 constant abrasive mass flow rate $(300 \mathrm{~g} / \mathrm{min})$.

3

4

5

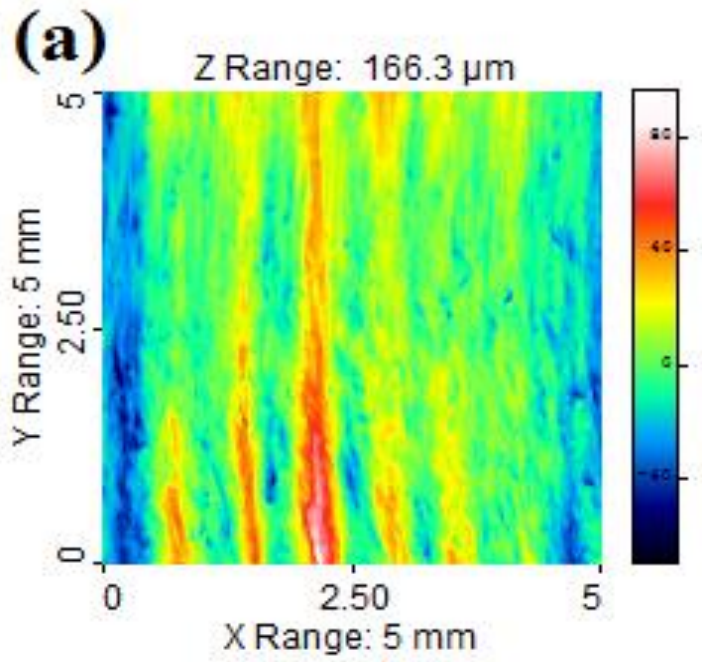

(b)

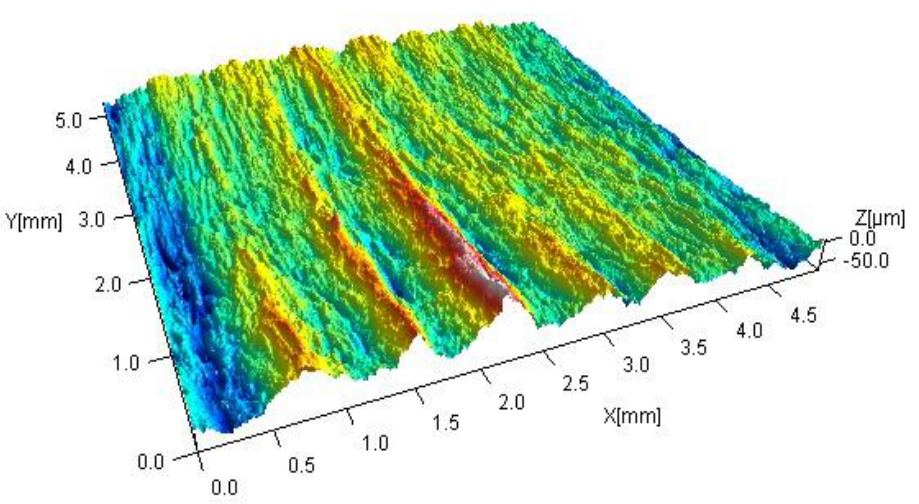

6 Fig. 10. Surface topographic image (a) 2D view, (b) 3D view of AWJ surface cut at $500 \mathrm{~mm} / \mathrm{min}$ 7 speed.

8

9

10

11

12

13

14

15 

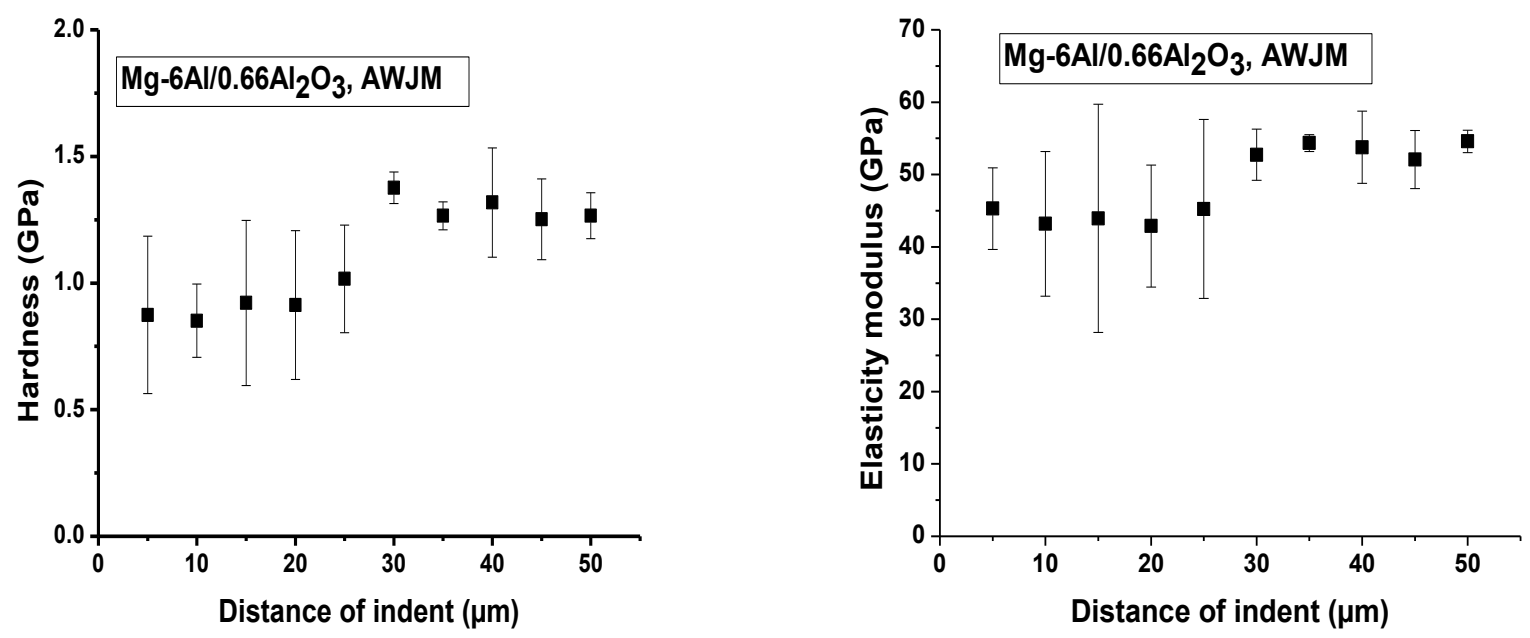

1 Fig. 11. Hardness and modulus values as a function of distance of indentation (across thickness) 2 from machined surface.

Table No. Table captions

Table $1 \quad$ Machining condition of AWJ cutting

Table 2 Results of density, hardness and elastic modulus of $\mathrm{Mg}-6 \mathrm{Al} / 0.66 \% \mathrm{Al}_{2} \mathrm{O}_{3}$ nanocomposites. 
13 Table 1: Machining condition of AWJ cutting

\begin{tabular}{|c|c|c|c|}
\hline \multicolumn{4}{|c|}{ AWJ device for cutting by PTV: CNC WJ2020B-1Z-D } \\
\hline \multicolumn{4}{|c|}{ Material :- Mg-6Al/0.66\% $\mathrm{Al}_{2} \mathrm{O}_{3}$} \\
\hline Parameters & Symbols & Unit & Value \\
\hline Pressure of water & $p$ & $\mathrm{MPa}$ & 400 \\
\hline Traverse speed & $v_{t}$ & $\mathrm{~mm} / \mathrm{min}$ & Variable $20,250,500$ \\
\hline Thickness of sample & $h$ & $\mathrm{~mm}$ & 8 \\
\hline Abrasive mass flow rate & $m_{a}$ & $\mathrm{~g} / \mathrm{min}$ & 300 \\
\hline Abrasive size & - & mesh & 80 \\
\hline
\end{tabular}




\begin{tabular}{lccl}
\hline Water nozzle diameter & $\varnothing d_{o}$ & $\mathrm{~mm}$ & 0.33 \\
Focusing tube diameter & $\varnothing d_{f}$ & $\mathrm{~mm}$ & 0.9 \\
Stand-off distance & $z$ & $\mathrm{~mm}$ & 2 \\
Position of cutting head & $\varphi$ & $\circ$ & 90 \\
Abrasives Used & - & - & Australian garnet \\
\hline
\end{tabular}

1

2

3

4

5

6

7

8

9

10

11

12 Table 2: Results of density, hardness and elastic modulus of $\mathrm{Mg}-6 \mathrm{Al} / 0.66 \% \mathrm{Al}_{2} \mathrm{O}_{3}$ 13 nanocomposites.

\begin{tabular}{llll}
\hline Material & Density $\left(\mathrm{g} / \mathrm{cm}^{3}\right)$ & Hardness $(\mathrm{GPa})$ & Elastic Modulus $(\mathrm{GPa})$ \\
\hline Unreinforced $\mathrm{Mg}$ & 1.739100 & $0.6-0.8$ & $43-45$ \\
$\mathrm{Mg}-6 \mathrm{Al} / 0.66 \mathrm{Al}_{2} \mathrm{O}_{3}$ & 1.751204 & $0.8-1.2$ & $47-51$ \\
\hline
\end{tabular}


1

2

3

4

5

6

7

8

9

10

11

12 